\title{
Delayed complication of a retrievable inferior vena cava filter
}

\author{
Kruti R Patel ${ }^{* *}$, Matthew Tong ${ }^{1,2}$, Amit Nautiyal ${ }^{3}$, Gary Ansel ${ }^{2}$ and Jayanta T Mukherjee ${ }^{2}$ \\ ${ }^{1}$ Doctors Hospital, OhioHealth, Columbus, Ohio, USA \\ ${ }^{2}$ Riverside Hospital, OhioHealth, Columbus, Ohio, USA \\ ${ }^{3}$ Albany Medical Centre, Albany, New York, USA
}

40 year old female with history of hypertension, hyperlipidemia, atrial fibrillation and gastric bypass surgery six years ago with perioperative placement of Bard IVC filter at an outside institution presented with sudden onset, sharp, unrelenting chest pain and dyspnea on exertion. Her peak troponin was elevated with nonspecific ST and $\mathrm{T}$ wave changes on her electrocardiogram. She underwent left heart cardiac catheterization which was negative for coronary occlusions however fluoroscopy did demonstrate a foreign body in left lower distal branch of pulmonary artery and right ventricle. CT scan confirmed a presence of a linear metallic radio-opaque foreign body within the right ventricle extending into adjacent pericardial fat (Figure 1). Transthoracic echocardiogram confirmed the foreign body embedded in the right ventricle with extension into the pericardial space (Figure 2). Open heart approach was selected versus endovascular approach due to penetrating nature of the object as suggested on CT scan. A subxiphoid approach was used to create a pericardial window and pericardium was identified with bloody pericardial fluid. There was no evidence of foreign body penetrating through the ventricle as initially suggested by CT scan. Procedure was converted to median sternotomy for better visualization. There was no evidence of extracardiac foreign body penetrating through the surface of the heart upon palpation of surface. Ascending aorta, inferior vena cava and superior vena cava were cannulated and cardiopulmonary bypass was initiated. Right atrium was opened and tricuspid valve was elevated out to visualize the right ventricle. A metallic object was found penetrating into the right ventricular free wall. She underwent extraction of the sharp metallic object $(3.0 \mathrm{~cm} \times$ less than $0.1 \mathrm{~cm} \times$ less than $0.1 \mathrm{~cm})$ embedded in the right ventricle and percutaneous IVC filter retrieval (Figures 3 and 4).

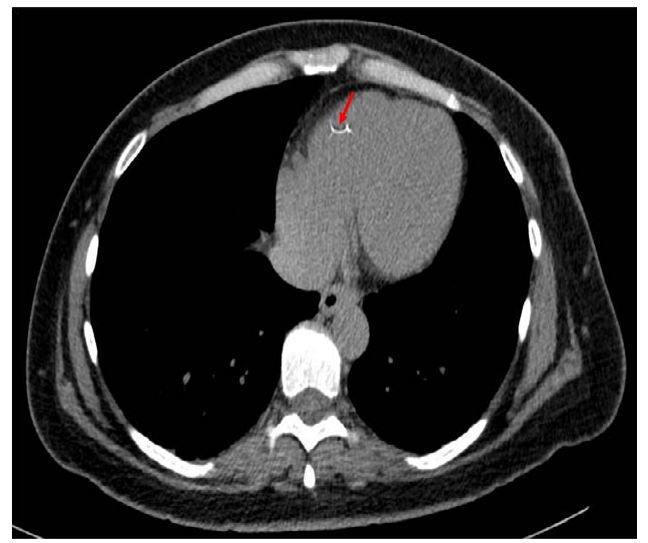

Figure 1. Axial slice of CT Chest showing the filter remnant in the right ventricle.
Her postoperative course was uncomplicated and she was discharged home with sternal wound healing precautions.

\section{Discussion}

Retrievable Vena Cava Filters are Food and Drug Administration (FDA) approved for pulmonary embolism prophylaxis and is only recommended in patients' who have an absolute contraindication to anticoagulation (Grade 1a). Retrievable IVC filters were designed to provide temporary protection from pulmonary embolism [1,2], however about $50 \%$ of the these implantations are not retrieved. In another single center retrospective study, of 679 IVC filters placements, only $8.5 \%$ were successfully removed and rate of filter fracture was found to be unusually high as $40 \%$ at 5.5 years [3].

Venous thromboembolic disease remains a major cause of morbidity and mortality. Familiarity with complications of IVC filter

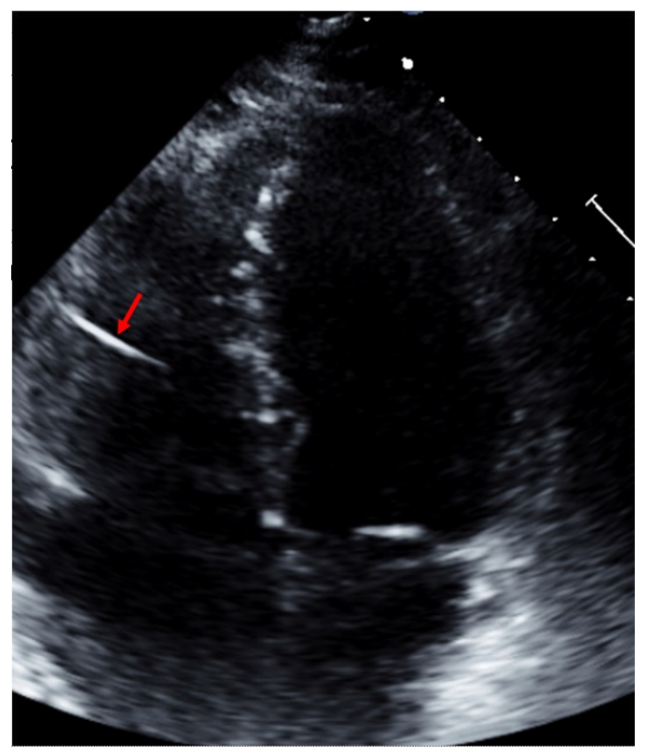

Figure 2. Trans-thoracic echocardiogram still image showing the filter remnant in the right ventricle.

Correspondence to: Kruti R Patel, DO, Doctors Hospital, OhioHealth, Columbus, Ohio, USA, Tel. 848-391-9219, E-mail: Kruti.Patel@ohiohealth.com

Received: January 17, 2017; Accepted: February 06, 2017; Published: February 09,2017 


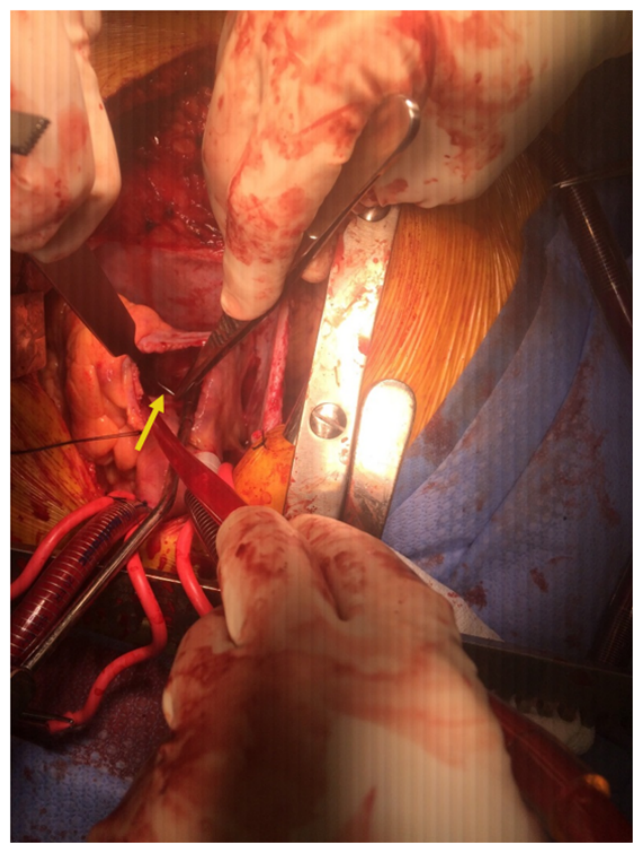

Figure 3. Intra-operative image showing the IVC filter remnant inside the right ventricular cavity.

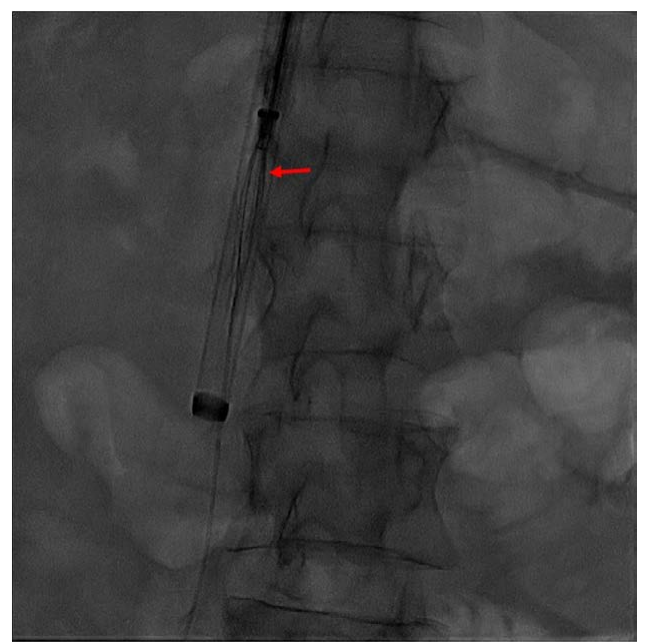

Figure 4. Still view of cineangiogram of IVC filter inside the sheath.

placement and retrieval may reduce the risks of these procedures. These complications can be divided into three categories: procedural complications- related to venous access and filter deployment; delayed complications- filter fracture, migration, IVC thrombosis and recurrent PE; filter retrieval complications [1]. Although serious complications of placement and removal of IVC filters are rare, there is very limited clinical evidence supporting safety of placement and long term complications. True incidence of IVC filter complications is difficult to determine due to significant variation in patient populations, filter types, comorbid conditions and variability in follow up duration. Factors such as route and technique, indication for placement, category/ size of filter and timing of retrievable filters should also be taken into consideration to decrease rate of complications. Complications of IVC filters are numerous pulmonary embolism, duodenal and aortic perforations, caval thrombosis, post thrombotic syndrome, migration to right atrium, right ventricle and pulmonary artery and should not be ignored [1,4]. Less than 30 cases of IVC filter fracture with cardiac migration has been reported in the literature [5-7].

The Bard Recovery filter was designed to be permanent with ability to serve as a retrievable filter. Filter design consists of two levels of 6 radially distributed nitinol arms and legs which anchor the filter in the inferior vena cava and trap any embolizing clot [8].

Nicholson, et al. describes a retrospective analysis of 189 patients with implantation of the Bard Recovery or Bard G2 vena cava filter (on market since April 2004). 35 patients of 189 had died by the time of study data collection. Thirteen of 80 patients who underwent fluoroscopy for planned retrieval were found to have at least 1 nitinol arm or leg fracture. The bard recovery filter had an overall fracture prevalence of $25 \%$ (7 of 28); 6 of these 7 had at least one fragment embolize to the heart or to the lungs. Bard G2 filter which was modified to improve fracture resistance by using longer arms with curved ends to reduce stress concentration at the apex, was notable to have $12 \%$ rate of fracture (6 of 52). Compared to Bard Recovery filters, Bard G2 filter had fractured strut which maintained position locally in the IVC near the original implantation site [8].

Concept of metal fatigue has been described as a potential contributor to filter fracture. Nitinol is intermetallic compound of Titanium and Nickel which has self expanding properties used for endovascular stenting in peripheral vascular disease and venous thromboembolism. Metal fatigue has been hypothesized as directly proportional to time that was allotted for metal to allow itself to be imbedded in the vasculature [9]. Lynch and Keluawala, et al. report an analysis of 174 Bard G2 filters which were successfully removed ( $97.7 \%$ success) without any difference in success rate despite timing of placement (greater or less than 180 days). Despite the success rate, the incidence of fracture (3.4\%) was notable in filters which were left in place for greater than 180 days [10].

\section{Conclusion}

It is important to note that timely removal of IVC filter and a multidisciplinary team approach to establish follow up for is crucial in these patients'.

\section{References}

1. Thuong G Van Ha (2006) Complications of inferior vena caval filters. Semin Intervent Radiol 23: 150-155.

2. Decousus H, Leizorovicz A, Parent F, Page Y, Tardy B, et al. (1998) A clinical trial of vena caval filters in the prevention of pulmonary embolism in patients with proximal deep-vein thrombosis. Prévention du Risque d'Embolie Pulmonaire par Interruption Cave Study Group. $N$ Engl J Med 338: 409-415. [Crossref]

3. SarosiekS, Crowther M, Sloan J (2013) Indications, complications, and management of inferior vena cava filters: the experience in 952 patients at an academic hospital with a level i trauma center. JAMA Intern Med 173: 513-517. [Crossref]

4. Veroux M, Tallarita T, Pennisi M, Veroux P (2008) Late complication from a retrievable inferior vena cava filter with associated caval, aortic, and duodenal perforation: A case report. J Vasc Surg 48: 223-225. [Crossref]

5. Patel SH, Patel R (2007) Inferior vena cava filters for recurrent thrombosis: curren evidence. Tex Heart Inst J 34: 187-194. [Crossref]

6. Rectenwald JE (2005) Vena cava filters: uses and abuses. Semin Vasc Surg 18: 166-175. [Crossref]

7. Bowles B (2016) Inferior Vena Cava Filter Fracture and Migration to the heart: A Review of the Literature and Case Report. University of Arizona College of MedicinePhoenix.

8. Nicholson W, Nicholson WJ, Tolerico P, Taylor B, Solomon S, et al. (2010) Prevalence 
of fracture and fragment embolization of bard retrievable vena cava filters and clinical implications including cardiac perforation and tamponade. Arch Intern Med 170: 18271831. [Crossref]

9. Andreas M, Stoeckel D (2010) Function and performance of nitinol vascular implants.
Open Med Devices 2: 32-41.

10. Lynch FC, Kekulawela S (2009) Removal of the G2 filter: differences between implantation times greater and less than 180 days. $J$ Vasc Interv Radiol 20: 1200-1209. [Crossref]

Copyright: $(\mathbb{C} 2017$ Patel KR. This is an open-access article distributed under the terms of the Creative Commons Attribution License, which permits unrestricted use, distribution, and reproduction in any medium, provided the original author and source are credited. 